\title{
The Importance of Costing in Coastal Management: Experience of Selangor, Malaysia
}

\author{
M. Zainora Asmawi and Tuminah Paiman
}

\begin{abstract}
This research investigates the importance of costing element in sustaining the coastal management initiative in Selangor, Malaysia. Thus, this research stems from the approach of financing coastal management to see the importance of budgeting in planning and managing coastal areas. The research attempts to examine and analyse the relationship between the implementation of coastal management and the costing impact. The study was undertaken in Klang District, Selangor based on data collection from interviews, consisting of government officials and coastal management practitioners, apart from obtaining secondary data from literature review and governments' documents. The results demonstrate that the level of success of implementation of coastal management programme is based on its approved costing. In a local context, the results indicate that the relationship between costing and coastal management has a positive pattern but does not establish a strong relationship, whereby the costing index is only 0.195 (the third ranking place). This situation shows that Selangor state does not emphasise on the importance of costing element in managing its coastal areas. This is due to the lack of attention given to the importance of coastal management in relation to the holistic approach of development practised in Selangor.
\end{abstract}

Index Terms-Costing, coastal management, relationship, Selangor.

\section{INTRODUCTION}

Globally, coastal management (CM) programmes have been regarded as vital management approach in delivering the coastal strategies towards achieving a sustainable coastal development. Over the years, it is increasingly seen as an effective management tool working across sectoral, disciplinary and institutional boundaries to manage coastal resources [1], [2]. CM has many positive implications to the environmental, social and economic sectors. Its universal framework is applicable to any desired country to fulfil the nation aspiration to moving ahead in physical and socio-economic development and growth. In this regards, the costing impact factor (CIF) has become a significant attribute in implementing coastal management initiatives. Many literatures demonstrate the influence and importance of costing in the practice of coastal management [3]-[6]. Thus, the underlying aim of this research is to examine and analyse the relationship between the implementation of coastal management initiatives and costing aspect. The objectives of the study are to:

1) Examine the level of success of financing $\mathrm{CM}$

Manuscript received October 25, 2014; revised May 13, 2015. This work was financially Ministry of Higher Education (MOHE) under Grant FRGS 0510-133.

The authors are with the International Islamic University Malaysia, Malaysia (e-mail: zainora@iium.edu.my, tuminah01@gmail.com). programmes; and

2) Suggest a mechanism of using the CIF in managing the financial part of CM.

The study was undertaken based on data collection from interviews, consisting of government officials at various levels and coastal management practitioners. In addition, secondary data was obtained from various government agencies, such as the Town and Country Planning Department (TCPD), Selangor and Klang Municipal Council (KMC). In the context of the study, the area of KMC, i.e. Klang District is chosen as the site. It consists of two mukims, namely Klang and Kapar. The size of the study area is 626.78 square $\mathrm{km}$ of land. Generally, Klang town is known as the Royal Town in Selangor and located $32 \mathrm{~km}$ south-west of Kuala Lumpur. There are several main islands in Klang such as the Pulau Ketam, Pulau Klang, Pulau Indah, Pulau Selat Kering, Pulau Pintu Gedong, Pulau Tengah and Pulau Che Mat Zin. Klang has a $53.75 \mathrm{~km}$ coastline. The district is bounded on the north by the Kuala Selangor District, on the east by Petaling District and on the south by Kuala Langat District.

The research encompasses two major disciplines in strengthening the concept of CM for the nation, namely town planning and financial aspect. The integration of these disciplines examines and analyses the implementation of CM, taking into consideration the actual experience of the Local Planning Authority (LPA) in managing their jurisdiction area. Hence, this research enables the understanding of integrating the budgeting element in coastal management from the context of LPA.

\section{PROBLEM STATEMENTS}

\section{A. LPAs Always Disregard the Importance of Costing in $C M$}

LPA always neglects the importance of costing impact factor in preparing their annual budget. This situation leads to insufficient budgeting, particularly in implementing initiatives in coastal management. The overall budgeting system within the administration of LPA always disregards the element of initiatives of coastal management.

\section{B. Costing Is Not a Priority in CM}

It is noticeable that the failure of coastal management initiatives to be priority of the LPA and other agencies that undermines its potential contribution to sustaining the development. When coastal management is not prioritised by the LPA, this makes coastal management efforts were understaffed and under-funded. Inadequate fiscal administration can lead to the mismanagement of funds, further derailing coastal management efforts. 
The questions this research attempts to answer are:

1) How and to what degree do costing impact factors play a role in the implementation of coastal management?

2) How can costing impact factor fully contribute to a successful coastal management?

\section{LITERATURE REVIEW}

\section{A. Component of Coastal Management}

The coast is essential to marine life and supports a large part of the world's living marine resources. It contains a variety of renewable and non-renewable natural resources associated with its land, air and water. In contrast to the natural system, coastal areas also house of human populations and provide the base for all human activities related to the use of marine resources. The intervention of human activities creates conflict in coastal management. Reference [7] informs that coast may be seen as a series of interlinked physical systems, comprising both offshore and onshore elements. It comprises both and natural and socio-economic systems. The coastal system can be divided into three elements as shown in Fig. 1.

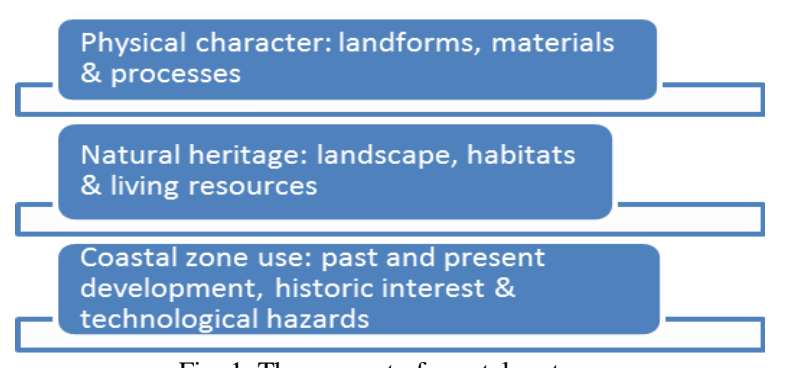

Fig. 1. The concept of coastal system.

Coastal zone management systems should generate decisions that deliver the goals of coastal management. The process of management has many facets which generate this outcome. The mix of outputs produced, when, where and for whom they are produced and what is the appropriate mix of products. The products comprise five elements:

1) Management activities

2) Detailed design of the physical measures and implementation incentive systems

3) Installation of components, including financial arrangements

4) Operation, maintenance and adjustment of the components

5) Monitoring and evaluation of the outcomes

\section{B. Costing Impact Factor (CIF)}

This research defines Costing Impact Factor (CIF) as "a quantitative way of assessing the worth of financial aspect and its degree of relevancy in specific field". In the context of this research, as it relates with coastal management field, therefore, it is named as CIFCOM (costing impact factor for coastal management). It is the cost involved in executing any works related to a coastal management project at different stages, ranging from planning, designing, construction, maintenance and so forth. This means that CIF is used to see the level of priority given by any agency, for instance, Klang Municipal Council in implementing its initiatives related to coastal management. CIF ranges from 0.0 to 1.0 . The reading indicates that the lower the CIF, the less priority of financial aspect in managing coastal area given by the agency and vice versa as shown in Fig. 2.

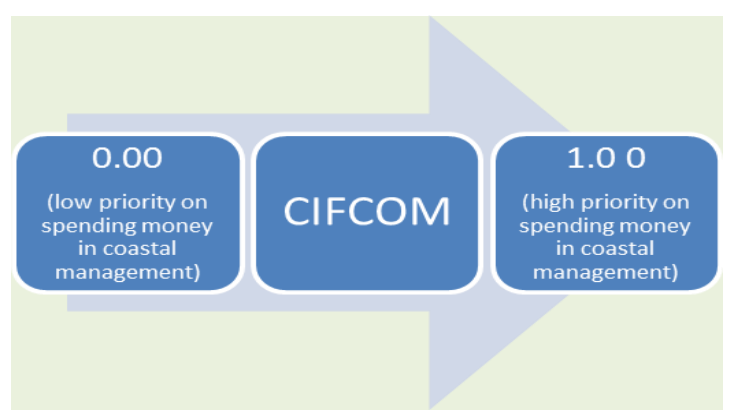

Fig. 2. The conceptual formulation of CIFCOM.

\section{The Importance of Financial Factor in Coastal Management}

Reference [3] state that the experience in the Philippines indicates that the success of most CM programmes in the islands depends, in part, on the ability of municipalities to secure adequate financial for CM initiatives. They further address that the desire to develop financing mechanisms capable of sustaining CM activities is great in that country. This indicates that the element of financial assistance is very essential in supporting the success of CM in which Malaysia could learn from this experience.

The financial factor is so vital in CM for several reasons. For instance, knowing the financial aspect in $\mathrm{CM}$ approach is significant especially in understanding the cost of undertaking one and ascertaining whether the outcomes are worth the money spent [4]. In addition, financial investment is considered as the backbone of CM [8]. Without the essential financial support, $\mathrm{CM}$ will not be hardly initiated and implemented. In Malaysia, research on the incorporation of financial impact factor in $\mathrm{CM}$ initiatives is currently unavailable. Though several programmes on CM have started and are on-going stages, no studies have tried to account the total level of investment. Experiences from other countries in the regional setting, e.g. the Philippines, also indicate that there is lacking of research on the relationship between costing and $\mathrm{CM}$, though some initiatives have taken to include the importance of costing element in supporting $\mathrm{CM}$ programmes.

Literature generally shows that the success of most CM programmes depends, largely, on the ability of municipalities to secure adequate financial for CM initiatives [5]. This is very obvious particularly when the authorities are seen as the main care taker of coastal areas. The costing element can be especially important in future planning of coastal areas, particularly if the sources of fund are limited.

\section{Costing Element in Coastal Management Programmes}

Knowing the costing aspect in coastal management approach is important especially in understanding the cost of undertaking one and ascertaining whether the outcomes are worth the money spent [4]. In addition, it is considered that financial investment is the essential backbone of coastal management [8]. Without the essential financial support, coastal management will not be initiated and implemented. In 
Malaysia, research on the incorporation of costing impact factor in coastal management initiatives is currently unavailable. Though several programmes on coastal management have started and are on-going stages, no studies have tried to account the total level of investment. Experiences from other countries in the regional setting, e.g. the Philippines, also indicate that there is lacking of research on the relationship between costing and coastal management.

Literature shows that the success of most coastal management programmes depends, largely, on the ability of municipalities to secure adequate financial for coastal management initiatives [3]. The costing element can be especially important in future planning of coastal areas, particularly if the sources of fund are limited. In Malaysia scenario, studies on the inter-relationship between coastal management, town planning and costing element are very limited either in academic line or practice.

LPA is responsible for the implementation of CM programmes in which they need to decide on the measures to be implemented in the maintenance and up-keep of the shoreline. These decisions have to be appropriate for the sustainability of the habitats. Reference [9] states that coastal habitats are valuable for the biodiversity of their fauna and flora while the dunes and wetlands provide flood control, drinking water, and waste assimilation, and beaches are valuable assets for tourism and recreation. He also addresses that tools for taking account of costs and benefits are necessary for the establishment of priorities in CM:

1) Between different areas in need of help because of the shoreline being threatened; and

2) Between different actions that could be taken that vary in their efficiency and effectiveness.

\section{E. The Relevance of Coastal Management in Town Planning}

Town planning (TP) system can be considered as an instrument of sustainable coastal development. Reference [1] mentions that planning system can be an instrument to achieve coastal management objectives through shaping and guiding of development and land use, through policies and proposals in development plans or similar documents and development control decisions. It can provide a statutory framework for coastal policy in a wider context. The TP system is designed to control development through its application system, and decisions are made in accordance with the planning authority's development plan. Some scholars such as [10], [11] examine TP elements in their studies of CM either in direct or indirect discussions. Otherwise, the contribution of the TP system to CM is little discussed in the academic world.

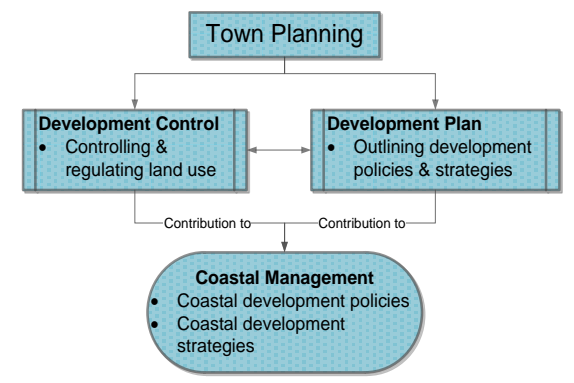

Fig. 3. A generic relationship between town planning and coastal management.
It is observed that $\mathrm{CM}$ has some objectives that can only be achieved by curtailing development. Only TP has the power that lies in a statutory regime. Therefore, $\mathrm{CM}$ must be able to communicate, co-ordinate, co-operate and collaborate in partnership efforts within the scope of TP. At a local level, the TP system can make a contribution to $\mathrm{CM}$ by using its development plan and development control systems (Fig. 3). Coastal policies could be incorporated into development plans and development control decisions made based on development plans.

The TP system is seen as one of the elements of a broader spectrum of CM. This is a positive statement suggesting that TP has a role to play in CM. The planning system can be an instrument to achieve $\mathrm{CM}$ objectives through the shaping and guiding of development and land use, through policies and proposals in development plans or similar documents and development control decisions. It can definitely provide a statutory framework for coastal policy in a wider context of general planning and development process. It can also bring together spatial aspects of multi-sectoral inputs into a single development planning system. Development plans can implement CM policy. It can also contribute by supplying information about development to other $\mathrm{CM}$ activities. The TP system is designed to control development through its application system, and decisions are made in accordance with the planning authority's development plan [1]. Development within the boundaries of local authorities will normally be subject to development control.

The challenge of coastal management respond to sustainable development is now recognised worldwide. Sustainable development is intended to find a balance between the economic, environmental and social aspects of people undertaking any development in coastal areas. Sustainability emerged very fast as the dominant paradigm of the world's coastal management programmes in the late twentieth century.

It is expected therefore that, in the future, all coastal management decisions will make sustainability their primary and main goal, and it will be the centrepiece of coastal management efforts at all levels of planning. Sustainability needs long-term policies and decisions that strengthen the resilience and integrity of natural and human made systems. Consequently, integration between Town and Country Planning act and coastal management are crucial since it supporting each other. Town and Country Planning Act 1976 (Act 172) is a strong base and supported by a legal statement and it must be follow by everyone. Since legal issues handle by the act, it can strengthen the enforcement of coastal management. It seems that the co-existence of related areas of financial aspect, TP and CM can become the main reason for a successful relationship towards achieving the notion of sustainable coastal development for the nation.

\section{Methods AND MATERIALS}

The research activity is divided into three phases. Table I summarises the activities by showing the sequence of activities undertaken in each phase. The first phase explores the fundamental ideas and principles behind the entire research exercise and helps develop the thinking behind the 
choice of research methods. Fieldwork was conducted during the second stage and the results will be analysed by using descriptive method. The last phase concerns a synthesis of all material and the development of the research recommendations. It provides the material for the conclusions of the research. As expected, the required information is needed to understand the relationship between coastal management and costing impact factor would be difficult to find as not many coastal management initiatives have been undertaken in Malaysia. Therefore, a few of methods is planned in the research, consisting of: document analysis of literature review; fieldwork, and conducting an in-depth interview survey with key-informants of KMC.

TABLE I: OUTLINE OF RESEARCH METHOD

\begin{tabular}{ll}
\hline \hline Phase & Main activities \\
\hline First phase (preliminary & Background study; reviewing literature \\
works) & review \\
Second phase (data & Fieldworks; office visits and interviews \\
collection) & the officials (8 senior officers) \\
Third phase (data analysis \& & Analysing the data; formulation of CIF in \\
recommendation) & coastal management \\
\hline \hline
\end{tabular}

\section{RESULTS AND DISCUSSION}

The state of Selangor does not have any specific unit or division on coastal management programme. It is done fragmentally by different agencies, depending on their scopes of works. For instance, the overall yearly budget of KMC can be divided into maintenance, services and assets. However, it covers the entire development and planning of various sectors ranging from infrastructure, public facilities and others. Therefore, minor adjustment on the data needs to be done as the total expenditure covers all sectors and not only for coastal management efforts. Based on the information gathered from the officers of KMC, it is assumed that coastal management efforts only utilised approximately 10-20\% of the overall yearly budget. Having said that, the budget spent on coastal management initiatives received little attention and does not carry a high priority of concern from the agency.

TABLE II: THE DISTRIBUTION OF MONEY SPENT ON COASTAL MANAGEMENT (AT IMPLEMENTATION STAGE) IN KLANG DisTRICT, 2006-2010 (IN PERCENTAGE)

\begin{tabular}{llllll}
\hline \hline Activity & 2006 & 2007 & 2008 & 2009 & 2010 \\
\hline Maintenance & 6.16 & 5.57 & 6.23 & 6.10 & 6.73 \\
Services & 93.20 & 93.90 & 92.10 & 92.10 & 92.50 \\
Assets & 0.52 & 0.54 & 1.66 & 1.00 & 0.82 \\
\hline \hline
\end{tabular}

Table II shows that information obtained from KMC for five consecutive years (2006-2010), services required the biggest portion of annual budget, i.e. more than $90 \%$ of the overall budget. Services cover works like landscaping work and rubbish collection. This is followed by maintenance (around 5-6\%) and assets (1\%).

The budget spent for five years (2006-2010) demonstrates that the pattern is nearly similar. Consequently, this influences the results of CIFCOM for the period of 2006-2010. As mentioned before, the allocation for coastal management efforts only require between $10-20 \%$ of total yearly expenditure. For the purpose of getting the information of the lowest and highest rate, therefore the readings of CIFOM for
2006-2010 are calculated at $10 \%$ and $20 \%$ respectively. The formula of CIFCOM is based on the Likert Scale in which each scale represents prioritisations of spending budgets. The formula is:

$$
\mathrm{CIFCOM}=\sum \frac{(5 n 5+4 n 4+3 n 3+2 n 2+1 n 1)}{5(n 5+n 4+n 3+n 2+n 1)}
$$

where $n 5, \mathrm{n} 4, n 3, n 2$ and $\mathrm{n} 1$ equal number of responding index.

The CIFCOM readings for 2006, 2007, 2008, 2009 and 2010 (at the rate of $10 \%$ and $20 \%$ on coastal management-related programmes) are shown in Table III. Generally the trend of CIFCOM over the five years did not have any significant readings whereby the growth of CIFCOM is rather stagnant.

TABLE III: CIFCOM FOR KLANG DISTRICT, 2006-2010

\begin{tabular}{llllll}
\hline \hline Activity & 2006 & 2007 & 2008 & 2009 & 2010 \\
\hline \multicolumn{7}{l}{ Scenario 1: lower importance } \\
Rate of 10\% & $0.9748 *$ & 0.9779 & $0.9680 *$ & $0.973 *$ & $0.9726 *$ \\
& 0.1 & $* 0.1$ & 0.1 & 0.1 & 0.1 \\
CIFCOM & 0.097 & 0.100 & 0.097 & 0.097 & 0.097 \\
Ranking & No. 3 & No. 3 & No. 3 & No. 3 & No. 3 \\
Scenario 2: higher importance & & & \\
\multicolumn{7}{l}{ Rate of 20\% } & $0.9748 *$ & 0.9779 & $0.9680 *$ & $0.973 *$ & $0.9726 *$ \\
CIFCOM & 0.2 & $* 0.2$ & 0.2 & 0.2 & 0.2 \\
Ranking & 0.195 & 0.196 & 0.194 & 0.195 & 0.195 \\
\hline \hline
\end{tabular}

The practice of coastal management in Klang district did not show an encouraging results. Though at the assumption of $20 \%$ of the expenditure spent yearly on coastal management initiatives, CIFCOM results demonstrate that the ranking is no. 3 , which means that coastal management has the least significant in the overall planning and development in the district of Klang. Assuming that only $10 \%$ of total annual expenditure goes to coastal management, the scenario of CIFCOM is even worse. The trend of CIFCOM as an indicator reflecting the importance of managing coastal areas for five consecutively years demonstrates that Klang has relatively stable growth of weak relationship between financial aspect and coastal management.

\section{CONCLUSION}

From the analysis, it shows that the readings of CIFCOM is highly depended on the allocation given to the efforts of coastal management. This is the key factor that influences the reading of CIFCOM. As addressd in the literature review, many scholars suggest that financial aspect will eventually faciliate the implementation of coastal management programme. It is clearly evident that the success of the implementation of coastal management initiatives relies on the fund allocates to it. The relationship is in a positive manner, either it is a strong or weak relationship.

The second factor in CIFCOM indicates that the importance level also depends on the mechanism of the efforts in managing coastal areas. For instance, coastal management in Sabah has a specific unit of coastal management and this 
shows that the state government also regards coastal management as a priority at the state level. This opposite scenario will happen if there is no concentration on coastal management, meaning lacking of significance given to that particular area.

The analysis shows that a strong commitment from the Local Planning Authority is an essential factor for a succesful coastal management. Having a dedicated agency looking after the coastal area is the pre-requisite condition in managing coastal areas.

At a different perspective, CIFCOM also depends on the development agenda at the state level, meaning that it requires much greater support from other stakeholders. In this regards, the elements of political will, good governance, advanced technology, good infrastructure and others are required to ensure that the relationship between financial aspect and coastal management is established in a strong positive manner. Though the results of CIFCOM for Klang district is not so encoraging (ranking no. 3), there are still rooms for improvement in the future.

It is suggested that Klang Municipal Council to consider adopting an improved way of managing the financial aspect in the implementation of coastal management initiatives. It is hoped that the measurement of CIFCOM indicator can be used as a referencing point to see the level of priority given on spending 'wisely' on improving their coastal management programmes. It can be concluded that this research has met its research objectives and thus, offered some considerations for further research related to the field of CM, TP and costing element as its contrirbution to the body of knowledge as a whole.

\section{ACKNOWLEDGMENT}

The researchers would like to express their thanks to all the participants who gave their precious time and input at the data collection period which have been instrumental in shaping this report (especially to Majlis Perbandaran Klang). Thanks are also expressed to the Ministry of Higher Education (MOHE) for their support in funding this research under the FRGS, 2010 (reference no: FRGS 0510-133). We also wish to acknowledge the technical support given by the Research Management Centre (RMC) of International Islamic University Malaysia (IIUM). The opinions expressed herein are those of the researchers and do not necessarily reflect the views of the funder and the university.

\section{REFERENCES}

[1] M. Z. Asmawi, Integrated Coastal Management and Town Planning in Peninsular Malaysia: Concept and Practice, USA: VDM \& Co., 2010, ch. 3, pp. 36-38.
[2] M. D. A. L. Tissier, J. M. Hills, J. A. McGregor, and M. Ireland, "A training framework for understanding conflict in the coastal zone," Coastal Management, vol. 32, pp. 77-88, 2003.

[3] N. Milne and P. Christie, "Financing integrated coastal management: Experiences in Mabini and Tingloy, Batangas, Philippines," Ocean and Coastal Management, vol. 48, pp. 427-449, 2005.

[4] A. M. Salamanca, "The cost of action: CRM investment in the Philippines," World Fish Center Quarterly, vol. 26, no. 2, pp. 25-29, 2003.

[5] R. S. Pomeroy, E. G. Oracion, R. B. Pollnac, and D. A. Caballes, "Factors influencing the sustainability of integrated coastal management projects in the Philippines," Ocean and Coastal Management, vol. 48, issue 3-6, pp. 360-377, 2005.

[6] T. E. Chua, "Integrated coastal management," in Encyclopedia of Malaysia, Ong and Gong, Eds., vol. 6, pp. 132-133, Singapore: Archipeligo Press.

[7] Department of the Environment, "Coastal planning and management A review of earth science information needs," London: HMSO, 1995.

[8] R. B. Pollnac and R. S. Pomeroy, "Factors influencing the sustainability of integrated coastal management projects in the Philippines and Indonesia," Ocean and Coastal Management, vol. 48, issue 3-6, pp. 233-251, 2005.

[9] M. Persson, "Impact assessment and project appraisal in cases of coastal erosion," International Journal of Disaster Resilience in the Built Environment, vol. 1, issue 3, pp. 297-309, 2010.

[10] P. Allmendinger, A. Barker, and S. Stead, "Delivering integrated coastal-zone management through land-use planning," Planning Practice \& Research, vol. 17, issue 2, pp. 175-196, 2002.

[11] J. Taussik, "Collaborative planning in the coastal zone," $\mathrm{PhD}$ dissertation, Dept. Of Urban Planning, Cardiff, 2001.

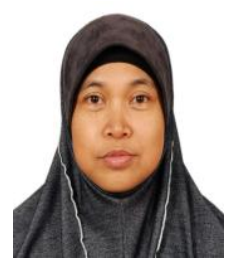

M. Zainora Asmawi was born in 1970 in Kuala Lumpur, Malaysia. She obtained her bachelor degree in the field of urban and regional planning from Technology University of Malaysia. She has a master of environment from Putra University of Malaysia and she pursued her $\mathrm{PhD}$ in coastal planning and management from the University of Portsmouth, United Kingdom.

She has produced several publications, such as "The perception of community on coastal erosion issue in Selangor, Malaysia," Journal of Clean Energy Technologies, etc. Her book entitled Integrated Coastal Management and Town Planning in Peninsular Malaysia: Concept and Practice published by VDM \& Co. in the USA (ISBN 978-3-639-26775-4). She has involved in many urban planning studies and works including in environmental studies.

Dr. Asmawi is a corporate town planner registered with the Malaysian Institute of Planners (MIP) and the board of Town Planners, Malaysia (BTPM). At a local level, her research work has won a gold medal in the IIUM Research Invention, Innovation and Exhibition (IRIIE) in 2011. She also had won a silver medal and a bronze medal in the same event in 2010 and 2009 respectively.

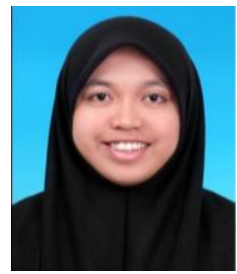

Tuminah Paiman was born in Sabah, Malaysia in 1986. She currently holds a bachelor degree in urban and regional planning from the International Islamic University Malaysia in 2010. She is currently pursuing her master in built environment (MSBE) at the same university with the interest in the environmental studies. She has presented several papers at the national and international level on the subjects of environmental and geographical information systems (GIS). She also involves in many consultancies works with the university as the town planner. 